\title{
VOLTAMMETRIC DETERMINATION OF TINIDAZOLE IN PHARMACEUTICAL TABLETS USING CARBON PASTE ELECTRODE
}

\author{
Abebe Taye and Meareg Amare* \\ Department of Chemistry, Bahir Dar University, P.O. Box 79, Bahir Dar, Ethiopia
}

(Received July 16, 2014; revised August 31, 2015)

\begin{abstract}
Cyclic voltammetry was used to study the electrochemical behavior of tinidazole at carbon paste electrode. Tinidazole showed an irreversible reduction peak at about $-440 \mathrm{mV}$. The differential pulse voltammetric peak current of tinidazole showed linear dependence on concentration in the range 5.0-200 $\mu \mathrm{M}$ with LOD and LOQ of $5.1 \times 10^{-7}$ and $1.7 \times 10^{-6} \mu \mathrm{M}$, respectively. Relative to most of the reported works on the determination of tinidazole, the developed method using carbon paste electrode which is an environmentally friendly, cheap, and simple working electrode exhibited linear dependence of peak current on concentration in the lower concentration region with relatively low LOD. Excellent recovery results with low \% RSD for spiked standard tinidazole in tablet samples showed the potential applicability of the developed method for the determination of tinidazole in real samples.
\end{abstract}

KEY WORDS: Carbon paste electrode, Differential pulse voltammetry, Tinidazole, Pharmaceutical tablets

\section{INTRODUCTION}

Compounds derived from nitroimidazole ring system (Table 1) form the basis of several important drugs exhibiting novel biological activities [1, 2]. Among these, metronidazole and tinidazole are well-known antimicrobial drugs as well as sensitizers of hypoxic tumors in conjunction with radiotherapy. The biological activity of nitroimidazole derivatives is dependent upon the nitro group reduction process due to the formation of active intermediate species that interact with DNA causing biochemical damage [3-5]. The small molecular size and low extent of protein binding of nitroimidazoles favor their distribution throughout the body.

Table 1. Structure of tinidazole and structurally similar N-derivatives.

\begin{tabular}{|l|l|}
\hline Substituent & Name \\
\hline $\mathrm{R}=\mathrm{CH}_{2} \mathrm{CH}_{2} \mathrm{OH}$ & Metronidazole \\
\hline $\mathrm{R}=\mathrm{CH}_{2} \mathrm{CH}(\mathrm{OH}) \mathrm{CH}_{2} \mathrm{Cl}$ & Omidazole \\
\hline $\mathrm{R}=\mathrm{CH}_{2} \mathrm{CH}_{2} \mathrm{SO}_{2} \mathrm{CH}_{2} \mathrm{CH}_{3}$ & Tinidazole (TNZ) \\
\hline
\end{tabular}

Tinidazole (1-(2-(ethylsulfonyl)ethyl)2-methyl-5-nitro-1H-imidazole) which is one of the nitroimidazole derivatives has been used as an antiprotozoal agent for many years in the treatment of infestations caused by Trichomonas vaginalis, Entamoeba histolytica and Giardia lamblia [6,7]. Furthermore, tinidazole (TNZ) has been used against anaerobic bacterial infections for prophylaxis in patients undergoing cystectomy or colorectal surgery and as a radio sensitizer [8,9]. Nowadays, TNZ is used in the treatment of adult periodontitis. TNZ is more effective than MTZ to kill the periodontal dominant anaerobic bacteria. Moreover, TNZ, in combination with amino penicillin, can be used to treat children infected with Helicobacter pylori [10].

\footnotetext{
*Corresponding author. E-mail: amaremeareg@yahoo.com
} 
Tinidazole is also widely used in the oral treatment of several protozoal infectionstrichomoniasis, giardiasis and amoebiasis. It is the most preferred choice of drug for intestinal ameobiasis $[11,12]$. The pharmacokinetic profile of tinidazole indicated that the drug is completely and promptly absorbed after oral administration [6]. Compared to metronidazole, tinidazole has a higher peak serum concentration, longer half-life, and less variation in blood levels. Recently, tinidazole has been used with a great deal of success in cases of metronidazoleresistant trichomoniasis [10].

The most common side effects reported with tinidazole are upset stomach, bitter taste, diarrhoea and itchiness. Other side effects which occur are headache, physical fatigue, and dizziness. Drinking alcohol while taking tinidazole causes an unpleasant disulfiram like reaction, which includes nausea, vomiting, headache and increased blood [13].

Analytical methods including HPLC [14-17] with different detectors and spectrophotometry $[7,18-23]$ have been reported on the determination of tinidazole in tablet, urine, and biological fluids. Since most of the conventional methods reported need trained personnel to operate, are expensive and not environmentally friendly, the development of electrochemical methods which are selective, sensitive, cheap and environmentally friendly is central.

Limited works have been reported on the application of electrochemical methods for the determination of TNZ in real samples like tablets, injection, urine and biological fluids [24-27]. Almost all reported electrochemical methods have used mercury as a working electrode making them still environmentally non-friendly. Carbon paste electrode is one of the carbon-based electrodes with low cost, easily renewable surface and very low back ground current making it superior over the $\mathrm{Pt}$ and $\mathrm{Au}$ electrodes [28]. The aim of this paper is thus to present an electrochemical method for the determination of tinidazole in pharmaceutical tablets using carbon paste electrode, which to the best of our knowledge is not reported.

\section{EXPERIMENTAL}

\section{Apparatus and instruments}

BAS 100B electrochemical analyzer [Bioanalytical Systems (BAS), USA] connected to a personal computer was used for the voltammetric measurements. A three electrodes system consisting of carbon paste electrode as working electrode, platinum coil as auxiliary electrode and $\mathrm{Ag} / \mathrm{AgCl}(3 \mathrm{M} \mathrm{NaCl})$ as reference electrode was used. The $\mathrm{pH}$ of the buffer solutions was measured with Jenway model $3310 \mathrm{pH}$ meter. An electronic balance (Denver instrument) was used for measuring mass of different chemicals and samples. A magnetic stirrer with a hot plate was used for stirring during $\mathrm{pH}$ adjustments.

\section{Chemicals and reagents}

Standard tinidazole (Emmelen Biotech Pharmaceuticals Limited) and tinidazole tablet of different brands (EPHARM, India, APF) were used. Graphite powder (BDH-Laboratory supplies Poole, England), paraffin oil (Abron Chemicals), Boric acid (BIO-lab laboratories LTD), phosphoric acid (EPARME COR), glacial acetic acid and $\mathrm{NaOH}$ (supplied by Blulux laboratories reagent), $\mathrm{HCl}$ (BDH Limited Poole, England) were used. Distilled water was used throughout the work.

\section{Preparation of carbon paste electrode}

Carbon paste electrode was prepared following the procedure reported elsewhere [29]. Briefly: 1 $\mathrm{g}$ of it was prepared by thoroughly mixing paraffin oil with graphite powder in a wt/wt ratio of 
28:72. The mixture was homogenized with mortar and pestle for $30 \mathrm{~min}$ and allowed to rest for $24 \mathrm{~h}$. The homogenized paste was packed in to the tip of a plastic tube (chewing gum stick, of about $3.5 \mathrm{~mm}$ diameter which was bought from an ordinary shop). A copper wire was inserted from the backside of the plastic tube to provide electrical contact. The surface of the electrode was smoothed manually against a smooth white paper until a shiny surface was created.

Preparation of tinidazole standard solutions

$1.0 \times 10^{-2} \mathrm{~mol} \mathrm{~L}^{-1}$ stock solution of tinidazole was prepared by dissolving an appropriate amount of tinidazole in $50 \mathrm{~mL}$ of $5 \%$ of ethanol with water. Tinidazole working solutions were prepared by diluting the stock solution with the $\mathrm{BRB}$ buffer solutions of the required $\mathrm{pH}$. The supporting electrolyte Briton Robinson buffers (BRB) in the $\mathrm{pH}$ range 2.5-4.5 were prepared from $\mathrm{H}_{3} \mathrm{BO}_{4}$, $\mathrm{CH}_{3} \mathrm{COOH}$ and $\mathrm{H}_{3} \mathrm{PO} 4$ each with $4.0 \times 10^{-2} \mathrm{~mol} \mathrm{~L}^{-1}$ in distilled water. $1.0 \mathrm{~mol} \mathrm{~L}^{-1} \mathrm{NaOH}$ and 1.0 $\mathrm{mol} \mathrm{L}{ }^{-1} \mathrm{HCl}$ solutions were used to adjust the $\mathrm{pH}$ of the buffer solution.

\section{Preparation of pharmaceutical tablet samples}

Tinidazole tablets (India, EPHARM, and APF) were purchased from pharmacies in Gondar town. Four tablets (labeled as $500 \mathrm{mg}$ tinidazole/tablet) of pharmaceutical formulations were accurately weighed and finely powdered in a porcelain mortar. An adequate amount of this powder, corresponding to a stock solution of concentration $1.0 \times 10^{-2} \mathrm{~mol} \mathrm{~L}^{-1}$ was weighed and transferred into a $50 \mathrm{~mL}$ flask and dissolved with $5 \%$ of ethanol solution. The tablet solutions were filtrated using a Whatman ${ }^{\circledR}$ filter paper. Then, 10.0, 50.0 and $100 \times 10^{-6} \mathrm{~mol} \mathrm{~L}^{-1}$ sample solutions were prepared from the stock solution using $4.0 \times 10^{-2} \mathrm{~mol} \mathrm{~L}^{-1} \mathrm{BRB}$ buffer solutions for each tinidazole tablet brand.

\section{Electrochemical procedure}

Both the $\mathrm{Ag} / \mathrm{AgCl}$ reference and $\mathrm{Pt}$ auxiliary electrodes were rinsed with distilled water prior to each measurement. The surface of the CPE was also smoothed manually against a smooth white paper. Voltammetric measurements were recorded using CPE working electrode after a stable voltammogram was obtained in BRB solution.

Cyclic voltammetric measurements were recorded in the potential window 0 to $-700 \mathrm{mV}$ at a scan rate of $100 \mathrm{mVs}^{-1}$. The influence of $\mathrm{pH}$ on the net peak current of tinidazole was investigated over $\mathrm{pH}$ range of 2.5-4.5. The effect of scan rate on both the reductive peak current and peak potential was investigated in the range 20 to $150 \mathrm{mVs}^{-1}$. Furthermore, differential pulse voltammetry was used for the quantitative determination of tinidazole in pharmaceutical samples. After a calibration curve was constructed using external standard addition of tinidazole solutions of different concentrations, the regression equation was used for the determination of the tinidazole content in tablets of different brands. All electrochemical measurements were conducted at a temperature range of $27 \pm 2{ }^{\circ} \mathrm{C}$.

\section{Statistical data analyses}

Data were analyzed using the Origin8.0 software and Statistical Package for Social Sciences (SPSS-16) software. Analysis of variance between groups (one way ANOVA) at confidence level of $95 \%$ was employed to evaluate whether detected amounts of TNZ in the three brands of tablets using the developed method were significantly different from each other or not. Results with p-values lower than 0.05 were considered as significantly (statistically) different and others as statistically equal. 


\section{RESULTS AND DISCUSSION}

\section{Electrochemical behavior of tinidazole at $C P E$}

Cyclic voltammetry was used to investigate the electrochemical behavior of tinidazole at carbon paste electrode. Figure 1 shows the cyclic voltammograms of CPE in $\mathrm{pH} 3.0$ BRB solution containing (a) no tinidazole and (b) $4.0 \times 10^{-4} \mathrm{~mol} \mathrm{~L}^{-1}$ tinidazole. The voltammogram of CPE in the buffer solution containing tinidazole showed a distinct irreversible reductive peak centered at about $-440 \mathrm{mV}$ (curve b) which is absent at the voltammogram recorded for CPE in the absence of tinidazole (curve a). Appearance of a single reductive peak at the CPE in response to tinidazole is in agreement with its response at single-wall carbon nanotube modified glassy carbon electrode reported [24].

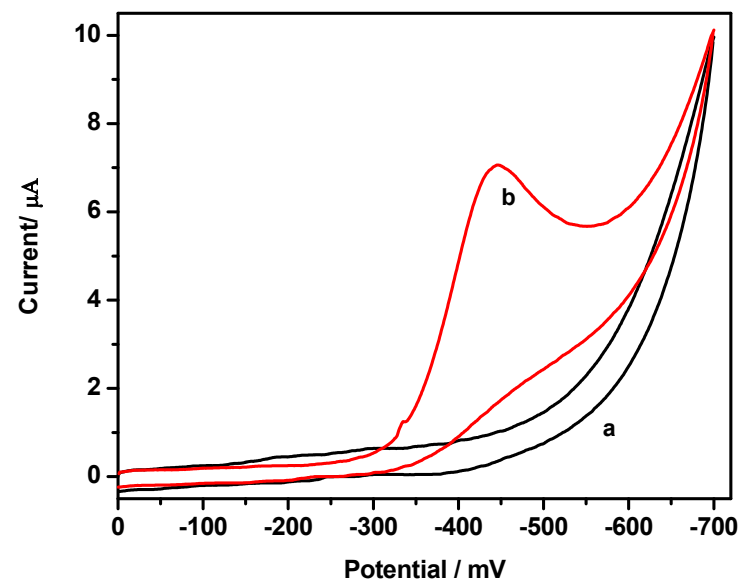

Figure 1. Cyclic voltammograms of CPE in $\mathrm{pH} 3.0 \mathrm{BRB}$ solution containing (a) no tinidazole and ( b) $4.0 \times 10^{-4} \mathrm{~mol} \mathrm{~L}^{-1}$ tinidazole; scan rate: $100 \mathrm{mV} \mathrm{s}^{-1}$; potential window: 0 to $700 \mathrm{mV}$.

Effect of scan rate

Figure 2 presents the cyclic voltammograms of $\mathrm{CPE}$ in $\mathrm{pH} 3.0$ BRB solution containing $4 \times 10^{-4} \mathrm{~mol} \mathrm{~L}^{-1}$ tinidazole at different scan rates. As can be seen from the figure, the increase in cathodic peak current $\left(I_{p c}\right)$ with scan rate was accompanied by peak potential shift in the negative direction.

In order to investigate whether the reduction kinetics of tinidazole at CPE is predominantly diffusion controlled or surface confined process, the dependence of peak current on the scan rate and square root of scan rate was studied. Inset of Figure 2 shows plot of $I_{p c}$ (cathodic peak current) of tinidazole versus $v$ (scan rate). In contrast to the correlation coefficient of 0.9922 for the dependence of cathodic peak current on the square root of scan rate (data not shown), an improved correlation coefficient $\left(\mathrm{R}^{2}\right)$ of 0.9964 was obtained for the linear dependence of cathodic peak current on the scan rate showing that the kinetics of the reduction of tinidazole at carbon paste electrode is predominantly adsorption controlled [30]. Taking the integrated peak area of the peak at scan rate of $100 \mathrm{mV} / \mathrm{s}$ in Figure 2, the number of electrons participated in the rate determining step was estimated using equation 1 at a temperature of $31{ }^{\circ} \mathrm{C}$ [31] to be 4.3 $(\approx 4)$. 
$n=\frac{4 i_{p, c} R T}{F Q \nu}$

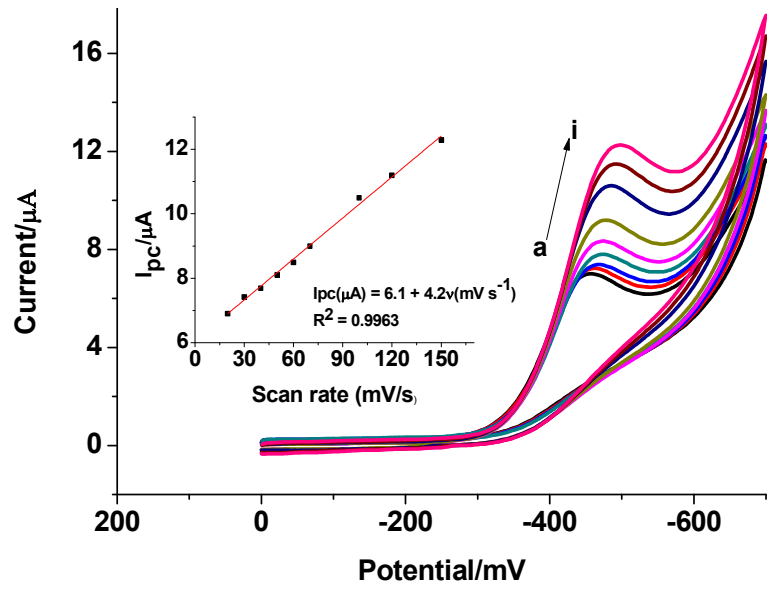

Figure 2. Cyclic voltammograms of $\mathrm{CPE}$ in $\mathrm{pH} 3 \mathrm{BRB}$ containing $4.0 \times 10^{-4} \mathrm{~mol} \mathrm{~L}^{-1}$ tinidazole at various scan rates (a-i: 20.0, 30.0, 40.0, 50.0, 60.0, 70.0, 100, 120 and; $150 \mathrm{mV} / \mathrm{s}$, respectively). Inset: Plot of peak current versus scan rate.

\section{Effect of $p H$}

The effect of $\mathrm{pH}$ on the reduction of tinidazole at $\mathrm{CPE}$ was studied in the $\mathrm{pH}$ range 2.5-4.5. The cyclic voltammograms of $0.4 \mathrm{mM}$ of tinidazole in BRB of various $\mathrm{pH}$ are shown in Figure 3 . Figure 4(a) represents the dependence of peak current response on the $\mathrm{pH}$ of the solution. As shown from the figure, the cathodic peak current response increased sharply from $\mathrm{pH}$ 2.5-3.0 and then decreased at $\mathrm{pH}$ values beyond 3.0. Therefore, $\mathrm{pH} 3.0$ was chosen as the optimum $\mathrm{pH}$ in the subsequent experiments which is in agreement with the previous report [26].

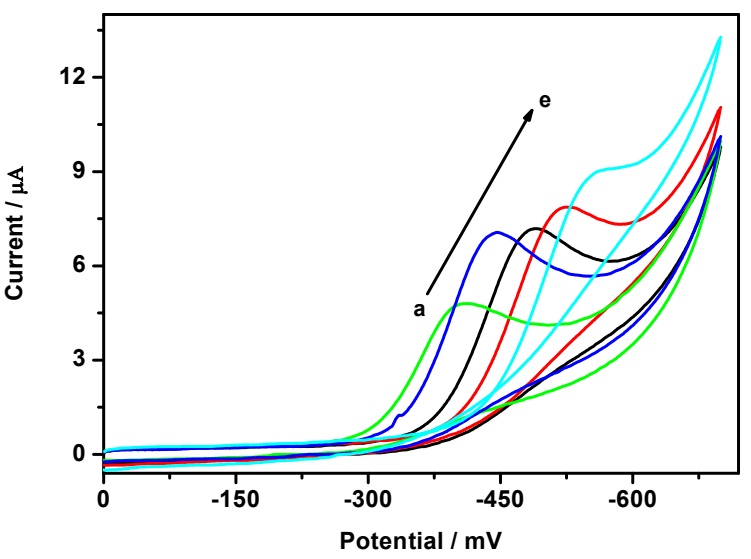

Figure 3. Cyclic voltammograms of CPE in BRB of different $\mathrm{pH}$ values (a-e: 2.5, 3, 3.5, 4.0 and; 4.5 , respectively) containing $4.0 \times 10^{-4} \mathrm{~mol} \mathrm{~L}^{-1}$ tinidazole. Scan rate: $100 \mathrm{mV} \mathrm{s}^{-1}$.

Bull. Chem. Soc. Ethiop. 2016, 30(1) 




Figure 4. Plot of (a) reductive peak current response versus $\mathrm{pH}$ and (b) peak potential as a function of the $\mathrm{pH}$ of BRB solution containing $4.0 \times 10^{-4} \mathrm{~mol} \mathrm{~L}^{-1} \mathrm{TNZ}$.

The influence of $\mathrm{pH}$ on the peak potentials of tinidazole was also examined. With increasing $\mathrm{pH}$, the reductive peak potential of tinidazole at CPE shifted in the negative potential direction indicating the participation of protons in the reduction of tinidazole [26]. As can be observed from Figure $4(b)$, a linear relationship between the peak potential and solution $\mathrm{pH}$ with a linear equation and correlation coefficient of $\mathrm{E}_{\mathrm{pc}}(\mathrm{V})=-0.3+-0.1 \mathrm{pH}$ and $\mathrm{R}^{2}=0.9978$, respectively was obtained. According to the Nernst equation at temperature $298 \mathrm{~K}$, a slope of $0.1 \mathrm{~V} / \mathrm{pH}$ suggests that the numbers of protons taking part in the electrode reaction are more or less equal to the number of electrons [32]. Since, number of electrons were estimated to be 4, a reaction mechanism was proposed (Scheme 1) for the reduction of tinidazole at carbon paste electrode which is in agreement with the previous report [24].

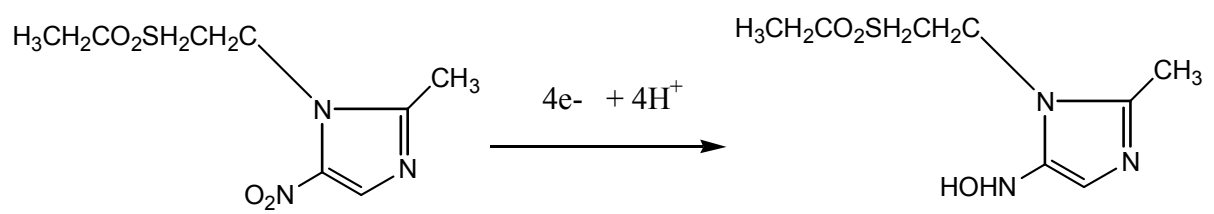

Scheme 1. Proposed mechanism for the reduction of tinidazole.

Differential pulse voltammetric investigation

The electrochemical reduction of tinidazole at carbon paste electrode was studied using differential pulse voltammetry in the potential range of 0 to $-650 \mathrm{mV}$. Figure 5 represents the differential pulse voltammograms of $\mathrm{CPE}$ in $\mathrm{pH} 3 \mathrm{BRB}$ in the absence $(a)$ andin the presence $(b)$ of $0.4 \mathrm{mM}$ tinidazole. No peak is observed at the voltammogram of CPE in buffer solution while there is an irreversible reductive peak in the presence of tinidazole.

Since the kinetics of the reduction of tinidazole at CPE is adsorption controlled, the accumulation $\left(E_{a c c}\right)$ and accumulation time $\left(t_{a c c}\right)$ were optimized. Moreover, method parameters such as scan rate; and pulse amplitude, were optimized. 


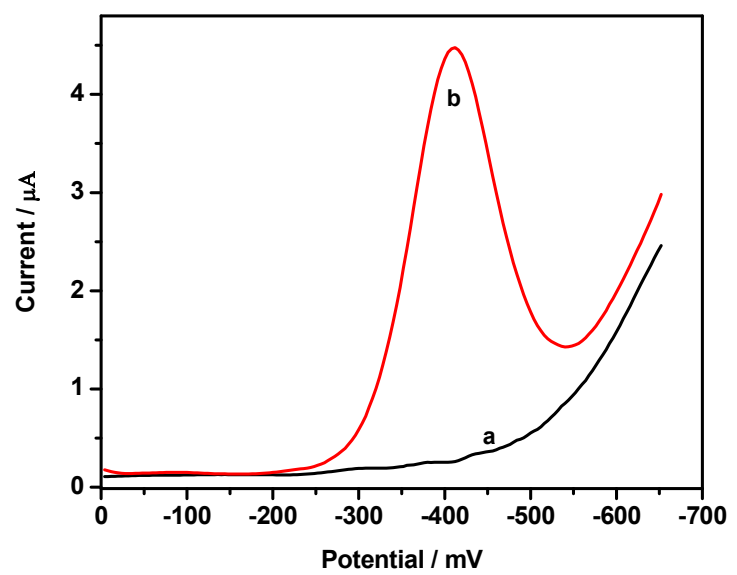

Figure 5. Differential pulse voltammograms of $\mathrm{CPE}$ in $\mathrm{pH} 3.0 \mathrm{BRB}$ solution containing (a) no TNZ and (b) $4.0 \times 10^{-4} \mathrm{~mol} \mathrm{~L}^{-1} \mathrm{TNZ}$.

Optimization of DPV scan rate and amplitude

The reductive peak current was observed to increase with increasing both the DPV scan rate and pulse amplitude (data not shown). The peak current increment was however accompanied by peak broadening and peak potential shift in the negative direction. Hence as a compromise between the peak current enhancement and peak broadening, a scan rate of $30 \mathrm{mV} / \mathrm{s}$ and amplitude of $40 \mathrm{mV}$ were taken as the optimum values.
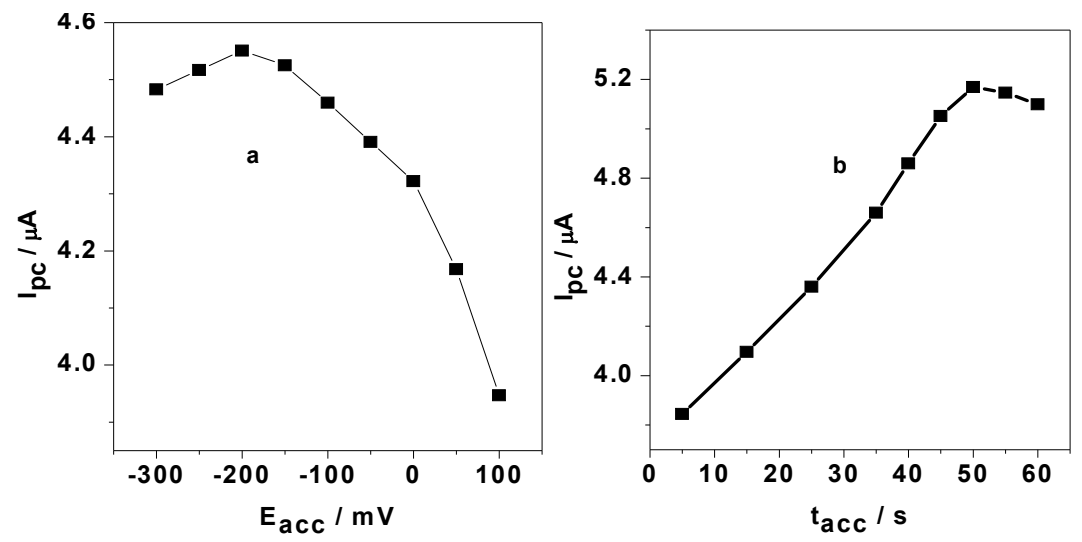

Figure 6. Plot of reductive peak current of $4.0 \times 10^{-4} \mathrm{~mol} \mathrm{~L}^{-1}$ tinidazole solution versus (a) $E_{a c c}$ at various accumulation potentials $(\mathrm{a}-\mathrm{i}:+100,+50,0,-50,-100,-150,-200,-250$ and $-300 \mathrm{mV}$, respectively) and (b) $t_{a c c}$ at various accumulation times (a-i: 5, 15, 25, 35, 40, $45,50,55$ and $60 \mathrm{~s}$, respectively). Scan rate: $30 \mathrm{mV} / \mathrm{s}$ and pulse amplitude: $40 \mathrm{mV}$. 


\section{Effect of accumulation potential}

Since the reduction reaction kinetics was adsorption controlled, the effect of accumulation potential and accumulation time on the magnitude of peak current response of CPE for $4 \times 10^{-4}$ mol L ${ }^{-1}$ tinidazole was investigated. Figure 6(a) shows the effect of accumulation potential $\left(E_{a c c}\right)$ over the potential range of +100 to $-300 \mathrm{mV}$ on the reductive peak current of TNZ at a constant accumulation time of $20 \mathrm{~s}$. As can be seen from the figure, the peak current increased with increasing the accumulation potential from +100 to $-200 \mathrm{mV}$. A peak current decrease was observed at accumulation potentials higher negative than $-200 \mathrm{mV}$ and hence, a preconcentration potential of $-200 \mathrm{mV}$ was taken as the optimum accumulation potential throughout the present work.

Figure $6(\mathrm{~b})$ presents plot of the reductive peak current of $4 \times 10^{-4} \mathrm{~mol} \mathrm{~L}^{-1} \mathrm{TNZ}$ as a function of the accumulation time $\left(t_{a c c}\right)$ at a constant $E_{a c c}$ of $-200 \mathrm{mV}$. As can be seen from the figure, the peak current increased with increasing the accumulation (deposition) time until it reached its maximum at $50 \mathrm{~s}$. At accumulation times longer than $50 \mathrm{~s}$, the peak current begun to decrease, which could be ascribed to the saturation of the electrode surface. Thus, an accumulation time of $50 \mathrm{~s}$ was selected as an optimum (deposition) time for this work.

Table 2. Summary of optimized solution and method parameters.

\begin{tabular}{|l|c|}
\hline Parameters & Optimized value \\
\hline $\mathrm{pH}$ of BRB solution & 3 \\
\hline Accumulation potential $\left(\mathrm{E}_{\mathrm{acc}}\right)$ & $-200 \mathrm{mV}$ \\
\hline Accumulation time $\left(\mathrm{t}_{\mathrm{acc}}\right)$ & $50 \mathrm{~s}$ \\
\hline DPV pulse amplitude & $40 \mathrm{mV}$ \\
\hline DPV scan rate & $30 \mathrm{mV} / \mathrm{s}$ \\
\hline
\end{tabular}

\section{Linear range and limit of detection}

Under the optimized solution and experimental conditions (Table 2), the dependence of reductive peak current response on the concentration of TNZ and the inherited sensitivity of the method were investigated. Figure 7 presents the differential pulse voltammograms of various concentrations of tinidazole. The subtracted (corrected for blank) reductive peak current showed linear dependence on the concentration in the concentration range $5.0 \times 10^{-6}-2.0 \times 10^{-4} \mathrm{~mol} \mathrm{~L}^{-1}$ (Inset of Figure 7) with a correlation coefficient, limit of detection (LOD $=3 \mathrm{~s} / \mathrm{slope}$ ) and limit of quantification $(\mathrm{LOQ}=10 \mathrm{~s} / \mathrm{slope})[33,34]$ of $\mathrm{R}^{2}=0.9980,5.1 \times 10^{-7}$ and $1.7 \times 10^{-6} \mathrm{~mol} \mathrm{~L}^{-1}$, respectively. At tinidazole concentrations lower than $5.0 \mu \mathrm{M}$, the Faradaic and capacitive currents were almost indistinguishable, whereas at concentrations larger than $2.0 \mathrm{mM}$, the slope of the regression line was observed to decrease which may be due to the saturation of the electrode surface.

The performance of the developed method for the detection of TNZ was compared with other reported methods as summarized under the Table 3 . As can be seen from the table, the developed method showed a relatively wider linear range and a comparable limit of detection even with the SWCNT/GCE, which is definitely much more expensive that the CPE. 


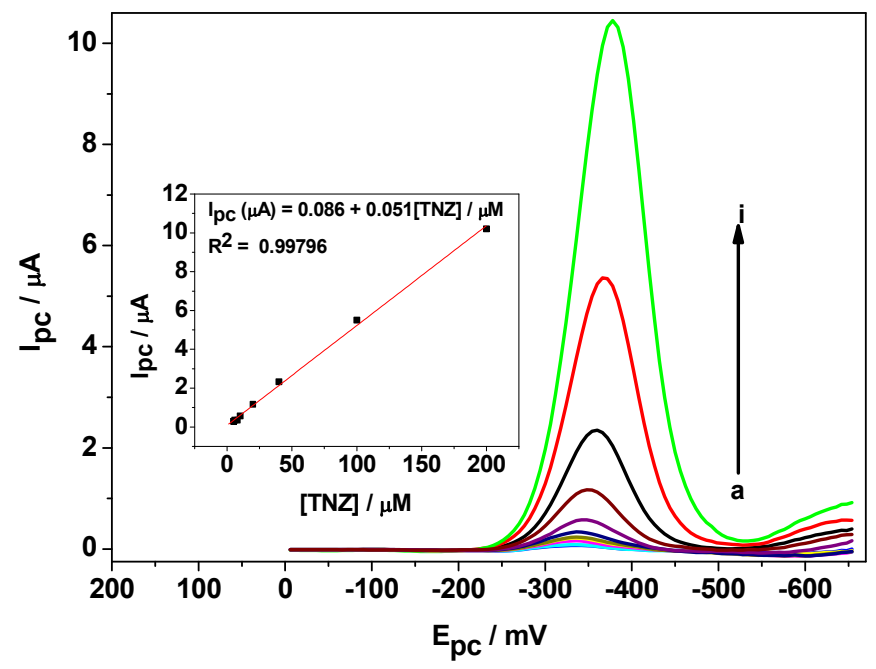

Figure 7. Differential pulse voltammograms of $\mathrm{CPE}$ in $\mathrm{pH} 3.0 \mathrm{BRB}$ solution containing various concentrations of tinidazole (a-h: 5.0, 6.0, 8.0,10.0, 20.0, 40.0, 100 and $200 \times 10^{-6}$ mol L ${ }^{-1}$, respectively. Inset: Plot of reductive peak current versus the concentration of tinidazole. $\mathrm{E}_{\mathrm{acc}}:-200 \mathrm{mV}, ; \mathrm{t}_{\mathrm{acc}}=50 \mathrm{~s}$; scan rate $=30 \mathrm{mV} / \mathrm{s}$; pulse amplitude $=40 \mathrm{mV}$.

Table 3. Comparison of the developed method with other reported methods.

\begin{tabular}{|l|l|l|l|c|}
\hline Electrode & Method & Linear range $\left(\mathrm{mol} \mathrm{L}^{-1}\right)$ & LOD $\left(\mathrm{mol} \mathrm{L}^{-1}\right)$ & Ref. \\
\hline SWCNT/GCE & DPV & $5.0 \times 10^{-8}-4.0 \times 10^{-5}$ & $1 \times 10^{-8}$ & 24 \\
\hline HMDE & DPCAdSP & $7.0 \times 10^{-9}-6.2 \times 10^{-7}$ & $4.5 \times 10^{-10}$ & 25 \\
\hline HMDE & DPP & $1.2 \times 10^{-7}-3.0 \times 10^{-5}$ & $1.2 \times 10^{-7}$ & 26 \\
\hline HMDE & DPP & $2.0 \times 10^{-6}-1.1 \times 10^{-3}$ & $9.7 \times 10^{-7}$ & 27 \\
\hline HMDE & LSCASP & $5.0 \times 10^{-7}-8.0 \times 10^{-6}$ & $4.5 \times 10^{-8}$ & 28 \\
\hline CPE & DPV & $5.0 \times 10^{-6}-2.0 \times 10^{-4}$ & $5.1 \times 10^{-7}$ & This work \\
\hline
\end{tabular}

\section{Real sample analysis}

The applicability of the developed method for the determination of TNZ in pharmaceutical tablets was investigated. The pharmaceutical tablet samples were weighed, dissolved, filtered, diluted and then added to the electrochemical cell for analysis as described in the experimental section. In this work, three sets (brands) of tinidazole tablets (APF, EPHARM, Indian) were selected for the analysis of tinidazole content. Based on the companies' labels, 10, 50, and 100 $\times 10^{-6} \mathrm{~mol} \mathrm{~L}^{-1}$ concentrations of each tablet brand were prepared following the procedure. The amount of TNZ found in each tablet brand is summarized in Table 4. In contrast to the amount of tinidazole expected as per to the label, amounts ranging from 78.6 to $95.3 \%$ were detected using the developed method. The observed lower amount of TNZ detected in all the brands could be attributed to losses during the laboratory sample preparation or possible degradations during the storage. The other trend observed from the table is that the results for the Indian brand samples are in general lower than similar samples of the other brands. Since the same procedure was followed, the cause for this could be either due to lower amount of TNZ per 
tablet or nature of the matrix. For all the analyzed tablet brands, the amount detected approached the labeled value for higher concentrations $(50$ and $100 \mu \mathrm{M})$ than for lower concentration $(10$ $\mu \mathrm{M})$. To further evaluate whether the detected amounts of TNZ in equal concentrations of tablet samples of different brands are significantly different or not, one way ANOVA statistical tool at $95 \%$ confidence level was employed. The p-value for the detected TNZ amounts in the $100 \mu \mathrm{M}$ and $50 \mu \mathrm{M}$ tablet samples of the three brands was found to be 1.000 indicating that the results were statistically not different. In contrast, $\mathrm{p}=0.001$ was obtained for the results in the $10 \mu \mathrm{M}$ tablet samples indicating that the results were statistically different. Further Tukey HSD one way ANOVA investigation on the results for the $10 \mu \mathrm{M}$ tablet samples of the three brands revealed that while the result for the Indian brand was significantly different from both the AF and EPHARM brands (p-values of 0.001 and 0.006 , respectively), the detected amounts in the $10 \mu \mathrm{M}$ tablet samples of AF and EPHARM brands are statistically equal $(\mathrm{p}=0.006)$. Statistical similarity of the detected amounts of TNZ in the three brands at 50 and $100 \mu \mathrm{M}$ using the developed method confirmed the applicability of the method for the determination of TNZ in real samples.

Table 4. Summary of the TNZ content in different brands of TNZ pharmaceutical tablets.

\begin{tabular}{|l|c|c|c|c|c|c|}
\hline \multirow{3}{*}{ Brand } & $\begin{array}{c}{[\mathrm{TNZ}] \text { as per }} \\
\text { label }(\mu \mathrm{M})\end{array}$ & \multicolumn{3}{|c|}{ Trial No. } & Detected (mg/tablet) & \% detected \\
\cline { 2 - 6 } & 10 & $1^{\text {st }}$ & $2^{\text {nd }}$ & $3^{\text {rd }}$ & Mean $\pm \%$ RSD & \\
\hline \multirow{4}{*}{ AF } & 50 & 432 & 429 & 432 & $431 \pm 0.4$ & 86.2 \\
\cline { 2 - 6 } & 100 & 469 & 455 & 451 & $453 \pm 0.4$ & 90.6 \\
\hline \multirow{4}{*}{ EPHARM } & 10 & 441 & 444 & 441 & $471 \pm 0.4$ & 94.1 \\
\cline { 2 - 6 } & 50 & 465 & 466 & 462 & $464 \pm 0.5$ & 88.4 \\
\hline \multirow{3}{*}{ INDIAN } & 100 & 476 & 476 & 478 & $476 \pm 0.5$ & 92.9 \\
\cline { 2 - 6 } & 10 & 394 & 390 & 394 & $393 \pm 0.4$ & 78.6 \\
\cline { 2 - 6 } & 50 & 418 & 417 & 420 & $418 \pm 0.7$ & 83.6 \\
\hline
\end{tabular}

\section{Method validation}

The accuracy of the proposed method was also checked using recovery experiments by the internal standard addition method (addition of known amount of standard TNZ to a pre-analyzed dosage of TNZ tablet sample). Mean recovery and RSD\% results for $10 \mu \mathrm{M}$ standard TNZ spiked in $100 \mu \mathrm{M} \mathrm{TNZ}$ solution of the three tablet brands are summarized in Table 5. Recovery results and $\mathrm{RSD} \%$ values in the range 98.9 to $100 \%$ and $1.1-1.9 \%$, respectively, indicated excellent accuracy and precision of the developed method, respectively [35, 36].

Table 5. Percentage recovery of spiked TNZ from pharmaceutical tablets.

\begin{tabular}{|l|c|c|c|}
\hline Tablet & $\begin{array}{c}\text { Expected }(\mu \mathrm{M}) \\
(\text { Found }+ \text { added })\end{array}$ & *Found $\pm \%$ RSD $(\mu \mathrm{M})$ & Recovery (\%) \\
\hline APF & 104 & $104 \pm 1.3$ & 100 \\
\hline EPHARM & 105 & $105 \pm 1.1$ & 100 \\
\hline INDIA & 99 & $98 \pm 1.9$ & 98.9 \\
\hline
\end{tabular}




\section{CONCLUSION}

Cyclic voltammetric investigation of tinidazole at CPE showed that the reduction of TNZ over the studied range of scan rates is irreversible. Investigation of the effect of $\mathrm{pH}$ and scan rate on the reduction of tinidazole at CPE revealed the participation of four electrons and four protons. A linear dependence of reductive peak current on the concentration of TNZ over a wide range of concentration with a relatively low detection limit, better selectivity and sensitivity, very good recoveries and easy electrode preparation illustrated the potential applicability of the developed method as an alternative method for the determination of tinidazole in real samples like pharmaceutical formulations.

\section{REFERENCES}

1. Chen, J.; Pattarawarapan, M.; Zhang, A.J.; Burgess, K. J. Comb. Chem. 2000, 2, 276.

2. Kodair, A.I.; Bertrand, P. Tetrahedron 1998, 54, 4859.

3. Lopez Nigro, M.M.; Gadano, A.B.; Carballo, M.A. Toxicol. In Vitro 2001, 15, 209.

4. Jose, V.M.; Sarafudheen, V. Indian J. Pharmacol. 2002, 34, 434.

5. Tocher, J.H.; Edwards, D.I. Biochem. Pharmacol. 1994, 48, 1089.

6. Fung, H.B.; Doan, T.L. Clin. Ther. 2005, 27, 1859.

7. Nabil, A.F.A.; Mohammed, H.A.S. Der Pharma Chemica 2012, 4, 2152.

8. Baggot, J.D.; Wilson, W.D.; Hietala, S. J. Vet. Pharmacol. Therap. 1988, 11, 417.

9. Sweeney, R.W.; Sweeney, C.R.; Soma, L.R.; Woodward, C.B.; Charlton, C.A. Am. J. Vet. Res. 1986, 47, 1726.

10. Robinson, D.M.; Abdel-Rahman, S.M.; Nahata, M.C. Ann. Pharmacother. 1997, 31, 1247.

11. Naikwade, S.R.; Kulkarni, P.P.; Jathar, S.R.; Bajaj, A.N. DARU J. Pharm. Sci. 2008, 16, 119.

12. Ahmed, T.; Ali, F.; Sarwar, S.G. Arch. Dis. Child. 1976, 51, 388.

13. Gennaro, A.R. Remington's Pharmaceutical Sciences, 18th ed., Mack Publishing Co.: Easton, PA; 1993.

14. Wang, Y.; Zhang, P.; Jiang, N.; Gong, X.; Meng, L.; Wang, D.; Ou, N.; Zhang, H. J. Chromatogr. B 2012, 899, 27.

15. Alton, K.B.; Patrick, J.E. J. Pharm. Sci. 1979, 68, 599.

16. Ouyang, L.Q.; Wu, H.L.; Liu, Y.J.; Wang, J.Y.; Yu, Y.J.; Zou, H.Y.; Yu, R.Q. Chin. Chem. Lett. 2010, 21, 1223.

17. Pasha, K.; Ali, A.; Bana, S.; Humair, S. Int. J .Pharm. Pharm. Sci. 2010, 2, 46.

18. Adegoke, O.A.; Umoh, O.E.; Soyinka, J.O. J. Iran. Chem. Soc. 2010, 7, 359.

19. Adegoke, O.A.; Umoh, O.E. Acta Pharm. 2009, 59, 407.

20. Pavan Kumar, G.V.S.R.; Chandra Sekhar, T.; Madhuri, R.G.S; Sreerama Murty, B. Int. J. Appl. Biol. Pharm. 2012, 3, 173.

21. Dinesh, N.D.; Nagaraja, P.; Rangappa, K.S. Turk. J. Chem. 2004, 28, 335.

22. Okunrobo, L.O. World J. Chem. 2007, 2, 63.

23. Singh, L.; Nanda, S. East Cent. Afr. J. Pharm. Sci. 2011, 14, 75.

24. Yang, C. Anal. Sci. 2004, 20, 821.

25. Jain, R.; Rather, J.A. Colloids Surf., A: Physicochem. Eng. Aspects 2011, 378, 27.

26. Abu Zuhri, A.Z.; Al-Khalil, S.; Shubietah, R.M.; El-Hroub, I. J. Pharm. Biomed. Anal. 1999, $21,881$.

27. Salvi, V.S.; Sathe, P.A.; Rege, P.V. J. Anal. Bioanal. Techniques 2010, 1, 110.

28. Maleki, N.; Safavi, A.; Tajabadi, F. Electroanalysis 2007, 19, 2247.

29. Tunay, Z.; Şahin, I.; Nakiboglu, N. Int. J. Electrochem. Sci. 2011, 6, 6628.

30. Mazloum-Ardakani, M.; Rajabi, H.; Beitollahi, H.; Mirjalili, B.B.F.; Akbari, A.; Taghavinia, N. Int. J. Electrochem. Sci. 2010, 5, 147. 
31. Prodromidis, M.I.; Floruo, A.B.; Tzouwara-karayanni, S.M.; Karayannis, M.I. Electroanalysis 2000, 12, 1498.

32. Xiao, P.; Zhou, Q.; Xiao, F.; Zhao, F.; Zeng, B. Int. J. Electrochem. Sci. 2006, 1, 228.

33. Ermer, J. J. Pharm. Biomed. Anal. 2001, 24, 755.

34. Shabir, G.A. J. Chromatogr. A 2003, 987, 57.

35. Braggio, S.; Barnaby, R.J.; Grossi, P.; Cugola, M. J. Pharm. Biomed. Anal. 1996, 14, 375.

36. Laviron, E.J. J. Electroanal. Chem. 1980, 112, 11. 